\title{
Capim-elefante amonizado e farelo de cacau ou torta de dendê em dietas para ovinos em crescimento 1
}

\author{
Herymá Giovane de Oliveira Silva ${ }^{2}$, Aureliano José Vieira Pires ${ }^{2}$, Gleidson Giordano Pinto de \\ Carvalho $^{3}$, Cristina Mattos Veloso ${ }^{2}$, Fabiano Ferreira da Silva ${ }^{2}$
}

\author{
1 Projeto financiado pela UESB. \\ 2 Universidade Estadual do Sudoeste da Bahia - UESB, Departamento de Tecnologia Rural e Animal - DTRA, Praça da Primavera no 40, \\ Primavera, CEP: 45700-000, Itapetinga - Bahia. \\ 3 Graduando em Zootecnia - UESB.
}

RESUMO - Estudou-se o efeito da amonização do capim-elefante e da substituição parcial do concentrado padrão, à base de milho e farelo de soja, por concentrados contendo farelo de cacau ou torta de dendê sobre o desempenho de ovinos. Utilizaram-se 18 ovinos machos não-castrados da raça Santa Inês, com peso corporal médio de 22,6 kg, distribuídos em um delineamento inteiramente casualizado, em esquema fatorial $2 \times 3$ com três repetições. O período experimental teve duração de 77 dias: 14 dias de adaptação e três períodos de 21 dias para coleta dos dados. As dietas foram compostas de $60 \%$ de volumoso ( silagem de capim-elefante não tratado ou tratado com uréia) e $40 \%$ de concentrado. Utilizaram-se três concentrados, um à base de milho e farelo de soja, outro contendo milho, farelo de soja e farelo de cacau e outro contendo milho, farelo de soja e torta de dendê. Os consumos de matéria seca em \% PC foram menores entre os animais alimentados com concentrado contendo torta de dendê, entretanto, não houve diferença entre o concentrado padrão e aquele com farelo de cacau nem entre os volumosos. Também não houve interação volumoso $\times$ concentrado. O ganho de peso foi maior nos animais alimentados com o capim-elefante amonizado. A lucratividade parcial por kg de ganho de peso elevou com a amonização do capim-elefante e reduziu com a inclusão dos subprodutos no concentrado.

Palavras-chave: amonização, consumo, subprodutos, uréia

\section{Amnonizated elephant grass and cocoa meal or palm kernel cake in growing sheep diet}

\begin{abstract}
The effect of ammonization of elephant grass and the partial substitution of the standard concentrate based on corn and soybean meal by concentrates containing cocoa meal or palm cake on sheep performance was evaluated. A total of 18 Santa Inês male sheep, with average $22.6 \mathrm{~kg} \mathrm{BW}$, was allotted to a completely randomized design in a $2 \times 3$ factorial arrangment with three replications. The experimental period consisted of 77 days, with 14 days for adaptation and three periods of 21 days for data collection. The diets constituted of $60 \%$ forage (elephant grass no treated or treated with urea) and $40 \%$ concentrate. Three concentrates were used, one based on corn and soybean meal, other containing corn, soybean meal and cocoa meal, and another containing corn, soybean meal and palm cake. The dry matter intakes in \% BW were lower in the concentrate containing palm cake, however there was no difference between the standard and cocoa meal concentrates, nor for between forages. There was also no forage to concentrate interaction. Animals fed ammoniated elephant grass showed the greatest weight gain. The partial profitability per $\mathrm{kg}$ of weight gain raised with the ammonization and reduced with the inclusion of by-products in the concentrate.
\end{abstract}

Key Words: ammoniation, intake, byproducts, urea

\section{Introdução}

No Nordeste brasileiro, a produção animalé a atividade agropecuária que mais contribui para o crescimento na renda (IBGE, 2004). No entanto, no setor de produção de carne ovina, a demanda ainda é insuficiente, em virtude da baixa qualidade e da sazonalidade de oferta desses produtos. Nesta região, as condições climáticas adversas prejudicam o desenvolvimento dessa atividade, de modo que a estacionalidade na produção de forragens em determinadas épocas do ano consiste no principal fator da baixa produtividade do rebanho. 
O uso de fenos e silagens de plantas colhidas em estádio de maturação avançado, de forragens resultantes da colheita de sementes de gramíneas e leguminosas, de subprodutos agroindustriais e de resíduos de culturas anuais de inverno e verão pode ser uma alternativa para a suplementação animalno período de escassez de forragem.

A conservação do capim-elefante (Pennisetum purpureum Schum.) produzido na estação chuvosa é uma alternativa muito utilizada para suprir a escassez de volumosos na época seca (Wilson, 1997). Entretanto, quando ensilado no estádio inicial do desenvolvimento, apesar do melhor valor nutritivo (Ferrari Jr. \& Lavezzo, 2001), o capimelefante apresenta características indesejáveis ao processo de ensilagem, como elevado teor de umidade, alto poder tampão e baixo teor de carboidratos solúveis (Lavezzo, 1994). No entanto, a eficiência de utilização deste volumoso pode ser melhorada com o uso de tratamentos químicos.

A amonização tem sido utilizada no intuito de conservar forragens com alto teor de umidade, como silagens, e melhorar o valor nutritivo de volumosos de baixa qualidade por meio da redução na fração da fibra em detergente neutro (FDN) ou da parede celular (Carvalho et al., 2006), pelo aumento na digestibilidade do material tratado (Reis et al., 2001) e pelo fornecimento de nitrogênio não-protéico (NNP) (Cândido et al., 1999). As formas mais comuns de amonização são via amônia anidra $\left(\mathrm{NH}_{3}\right)$ ou uréia $\left(\mathrm{NH}_{2} \mathrm{COONH}_{2}\right)$ (Souza et al., 2002).

Bertipaglia et al. (2005), utilizando 5\% de uréia na amonização do feno deBrachiaria brizantha, observaram aumento do valor nutritivo em relação ao material nãotratado. Segundo Reis et al. (1991), uma das principais alterações na composição química da fração fibrosa de volumosos tratados com amônia é a solubilização da hemicelulose, que resulta em diminuição no conteúdo de FDN. Carvalho et al. (2006), estudando o valor nutritivo do bagaço de cana-de-açúcar amonizado com uréia, concluíram que a amonização com uréia promove melhora do valor nutritivo, comprovada pelo aumento do teor de proteína bruta (PB) e pela redução do conteúdo de FDN.

Associado ao tratamento químico de volumosos de baixa qualidade, o uso de fonte suplementar, como milho e farelo de soja, tem sido adotado com o objetivo de melhorar a qualidade nutricional das dietas para ruminantes. Apesar da elevada qualidade nutricional, esses alimentos concentrados são de alto custo, o que torna necessária a utilização de fontes alimentares alternativas (Silva et al., 2007).

Os subprodutos agroindustriais consistem em alternativa viável tanto do ponto de vista nutricional como econômico. No estado da Bahia, encontram-se em quantidades significativas o farelo de cacau (FC) e a torta de dendê (TD), que podem ser utilizados na alimentação animal. O farelo de cacau é o subproduto da retirada do tegumento antes da torrefação das sementes para produção de manteiga ou chocolate (Compêndio Brasileiro de Alimentação Animal, 1998). É encontrado no mercado da região a preços acessíveis, uma vez que o estado da Bahia detém toda a produção de cacau do Nordeste e 69,9\% da produção brasileira (IBGE, 2004). Estima-se que a produção brasileira desse subproduto no ano de 2003 foi de 19.678,8 toneladas (Silva et al., 2005).

A torta de dendê é o produto resultante da polpa seca do dendê, após moagem e extração do óleo (Compêndio Brasileiro de Alimentação Animal, 1998), que pode ser utilizado como fertilizante ou como componente de ração para animais. A produção brasileira de dendê, centrada nas regiões Norte e Nordeste, cresceu de 522.883 para 717.893 toneladas no período de 1990 a 2002 (IBGE, 2004).

Silva et al. (2005), utilizando farelo de cacau ou torta de dendê em substituição ao concentrado à base de milho e soja na alimentação de cabras em lactação, observaram redução de 32,5\% no consumo de matéria seca (MS) com a inclusão de $18,47 \%$ de farelo de cacau na MS da dieta. Nos animais alimentados com dietas contendo torta de dendê, não foram observadas diferenças.

Esta pesquisa foi realizada com o objetivo de avaliar o desempenho de cordeiros machos Santa Inês alimentados com dietas contendo capim-elefante amonizado ou nãoamonizado e farelo de cacau ou torta de dendê em substituição parcial ao concentrado à base de milho e farelo de soja na alimentação de ovinos.

\section{Material e Métodos}

O experimento foi realizado na Universidade Estadual do Sudoeste da Bahia, no Campus Juvino Oliveira, na cidade de Itapetinga. Foram utilizados 18 ovinos Santa Inês, machos não-castrados, com peso corporal médio de 22,6 kg. Os animais foram alojados em baias individuais cobertas e distribuídos em delineamento inteiramente casualizado, em esquema fatorial $2 \times 3$.

Utilizou-se silagem de capim-elefante tratado ou não com uréia e três concentrados: um à base de milho e farelo de soja; outro composto de milho, farelo de soja e farelo de cacau (FC); e outro composto de milho, farelo de soja e torta de dendê (TD), com três repetições.

O capim-elefante foi colhido em estádio de maturação avançado (90 dias após o corte) e, depois de picado e pesado, foi armazenado em dois silos superfície durante 120 dias e fornecido aos animais. Em um dos silos, adicionou uréia (5\%, com base na MS) no momento da ensilagem. 
Os tratamentos (Tabelas 1, 2 e 3) foram os seguintes: silagem de capim-elefante ( $\mathrm{SC}$ ) + concentrado padrão (base de farelo de soja + milho); $\mathrm{SC}+40 \%$ de farelo de cacau (40\%FC) em substituição ao concentrado padrão; SC + 40\% de torta de dendê (40\% TD) em substituição ao concentrado padrão; silagem de capim-elefante amonizado (SCA) + concentrado padrão; SCA + 40\%FC em substituição ao concentrado padrão e; SCA + 40\% TD em substituição ao concentrado padrão.

Os concentrados, isoprotéicos (Tabela 2), foram fornecidos aos animais duas vezes ao dia, às 7 h e às $13 \mathrm{~h} 30$ na proporção 60:40 volumoso:concentrado.

O experimento teve duração de 77 dias, divididos em 14 dias de adaptação, nos quais os animais foram vermifugados e marcados com brincos, e três períodos de 21 dias para coleta de dados. Foram coletados dados de pesagens e amostras de volumoso, concentrado e das sobras. Os animais foram pesados em jejum de 15 horas no início e ao final do período experimental.
Após coletas semanais, as amostras de volumoso, concentrado e das sobras foram acondicionadas em freezer, posteriormente congeladas e trituradas em moinho tipo Willey com peneira de 20 mesh. Foram avaliados os consumos de MS, PB, FDN e fibra em detergente ácido (FDA), segundo Silva \& Queiroz (2002). Os carboidratos totais (CT) foram calculados segundo Sniffen et al. (1992), de modo que os carboidratos fibrosos (CF) foram considerados como a FDN corrigida para o seu conteúdo em matéria mineral e proteína (FDNmp) e os carboidratos não-fibrosos (CNF) foram obtidos pela subtração da FDNmp dos carboidratos totais $(\mathrm{CT})$ :

$$
\begin{gathered}
\mathrm{CT}=100-(\% \mathrm{~PB}+\% \mathrm{EE}+\% \text { Cinzas }) \\
\mathrm{CNF}=\mathrm{CT}-\% \mathrm{FDNmp}
\end{gathered}
$$

A metodologia utilizada para obtenção da digestibilidade parcial e os valores dos coeficientes de digestibilidade dos nutrientes obtidos (MS, MO, FDN, FDA, PB, EE, CT e CNF) são descritos por Silva et al. (2007). Os teores de nutrientes digestíveis totais (NDT) foram calculados pelo somatório

\begin{tabular}{|c|c|c|c|c|c|c|}
\hline \multirow[t]{2}{*}{ Nutriente (\%) } & \multirow[t]{2}{*}{ Milho } & \multirow[t]{2}{*}{ Farelo de soja } & \multirow[t]{2}{*}{ Farelo de cacau } & \multirow[t]{2}{*}{ Torta de dendê } & \multicolumn{2}{|c|}{ Silagem $^{1}$} \\
\hline & & & & & Não amonizada & Amonizada \\
\hline MS & 89,91 & 89,99 & 89,65 & 91,61 & 23,08 & 23,28 \\
\hline PB & 9,49 & 47,42 & 13,45 & 14,78 & 4,69 & 7,14 \\
\hline $\mathrm{EE}$ & 4,06 & 3,21 & 7,89 & 6,22 & 2,18 & 2,30 \\
\hline FDN & 12,58 & 13,37 & 45,77 & 80,42 & 70,31 & 69,63 \\
\hline FDA & 3,42 & 8,98 & 38,91 & 46,43 & 34,23 & 36,74 \\
\hline Carboidratos totais & 83,06 & 45,96 & 70,19 & 74,93 & 82,77 & 77,92 \\
\hline Cinzas & 3,39 & 3,41 & 8,47 & 4,07 & 11,25 & 12,96 \\
\hline Lignina & 4,85 & 4,78 & 4,53 & 4,64 & 4,50 & 5,09 \\
\hline Hemicelulose & 9,16 & 4,39 & 6,86 & 33,99 & 36,08 & 32,89 \\
\hline Celulose & 30,57 & 38,52 & 33,11 & 27,73 & 29,73 & 31,65 \\
\hline
\end{tabular}

Tabela 1 - Composição nutricional dos ingredientes utilizados nas dietas experimentais

${ }^{1}$ Média dos três períodos.

\begin{tabular}{|c|c|c|c|}
\hline \multirow[t]{2}{*}{ Item } & \multicolumn{3}{|c|}{ Concentrado } \\
\hline & Controle & $40 \%$ de farelo de cacau & $40 \%$ de torta de dendê \\
\hline \multicolumn{4}{|l|}{ Ingrediente } \\
\hline Milho moído & 76,85 & 41,27 & 43,97 \\
\hline Farelo de soja & 20,19 & 16,17 & 13,47 \\
\hline Farelo de cacau & 0,00 & 39,59 & 0,00 \\
\hline Torta de dendê & 0,00 & 0,00 & 39,57 \\
\hline Mistura mineral & 2,96 & 2,98 & 2,98 \\
\hline \multicolumn{4}{|c|}{ Composição nutricional } \\
\hline PB & 16,87 & 16,91 & 16,41 \\
\hline EE & 3,77 & 5,32 & 4,68 \\
\hline FDN & 12,37 & 25,47 & 39,16 \\
\hline FDA & 4,44 & 18,27 & 21,09 \\
\hline Lignina & 4,69 & 4,57 & 4,61 \\
\hline Hemicelulose & 7,93 & 7,20 & 18,07 \\
\hline Celulose & 31,27 & 31,95 & 29,60 \\
\hline
\end{tabular}

Tabela 2 - Composição dos concentrados das dietas experimentais (\%MS) 
Tabela 3 - Composição nutricional das dietas experimentais

\begin{tabular}{|c|c|c|c|c|c|c|}
\hline \multirow[t]{2}{*}{ Nutriente } & \multicolumn{3}{|c|}{ Capim-elefante não-amonizado } & \multicolumn{3}{|c|}{ Capim-elefante amonizado } \\
\hline & Controle & $40 \%$ FC & $40 \% \mathrm{TD}$ & Controle & $40 \% \mathrm{FC}$ & $40 \%$ TD \\
\hline PB & 9,22 & 9,12 & 9,04 & 11,04 & 10,93 & 10,85 \\
\hline FDN & 47,13 & 52,37 & 57,85 & 46,72 & 51,96 & 57,44 \\
\hline FDA & 22,45 & 27,98 & 29,11 & 21,62 & 27,15 & 28,28 \\
\hline
\end{tabular}

$\mathrm{FC}=$ farelo de cacau; $\mathrm{TD}=$ torta de dendê

da proteína bruta digestível (PBD), da fibra em detergente neutro digestível (FDND) e do extrato etéreo digestível (EED), multiplicado por 2,25, e dos carboidra tos não-fibrosos digestíveis (CNFD), segundo Weiss (1999):

$$
\mathrm{NDT}=\mathrm{PBD}+\mathrm{FDND}+\mathrm{EED} \times 2,25+\mathrm{CNFD}
$$

Para o cálculo da energia digestível (ED), considerou-se que $1 \mathrm{~kg}$ de NDT equivale a $4.409 \mathrm{kcal}$ de energia digestível $(\mathrm{kcal}$ de $\mathrm{ED} / \mathrm{kg}$ de MS = \%NDT/100 × 4.409) e, no cálculo daenergia metabolizável (EM), utilizou-se o fator 0,82 multiplicado pela energia digestível (kcal EM/kg de $\mathrm{MS}=\mathrm{ED} \times 0,82)$. Além dessas variáveis, foram avaliados os ganhos de peso em $\mathrm{kg} / \mathrm{dia}$.

$\mathrm{Na}$ avaliação dos custos e das receitas, foram utilizados os valores, em reais, correspondentes a cada componente da dieta e ao preço do peso corporal do cordeiro acabado no período em que foi realizado o experimento.O custo das dietas foi calculado considerando o consumo de MS de silagem e de concentrado, não considerando os desperdícios no ato da alimentação e as obras no cocho.Na composição dos custos dos concentrados, considerou-se apenas o valor médio do preço de aquisição no mercado no ano de 2003, sem considerar a elaboração dos concentrados. Não foram considerados o custo da mão-de-obra para alimentar os animais, a depreciação das instalações e o custo financeiro dos recursos utilizados.

No cálculo do custo da silagem, consideraram-se os valores estimados para a região, acrescentando o valor da uréia e da mão-de-obra para silagem amonizada. A margem da operação foi obtida pela diferença entre a receita bruta e o custo da dieta: o custo do concentrado controle por $\mathrm{kg}$ de MS foi de R \$ 0,50; dos concentrados com inclusão de $40 \%$ de FC ou de $40 \%$ de TD, de R\$ $0,43 / \mathrm{kg}$ de MS; o da silagem não amonizada, de R $\$ 0,11$; e da silagem amonizada, de $\mathrm{R} \$ 0,14 / \mathrm{kg}$ de MS.

Os resultados foram analisados estatisticamente por meio de análises de variância e as médias, comparadas pelo teste Tukey a 5\% de probabilidade utilizando-se o Sistema de Análises Estatísticas e Genéticas - SAEG (UFV, 1998).

\section{Resultados e Discussão}

Verificou-se diferença $(\mathrm{P}<0,05)$ na ingestão de $\mathrm{MS}$, em percentual do peso corporal (\%PC), dos ovinos alimentados com concentrado padrão contendo $40 \% \mathrm{FC}$ em comparação aos alimentados com concentrado contendo 40\% TD (Tabela 4). Essa diferença pode ser explicada pela maior porcentagem de FDN deste concentrado, que atua como redutor do consumo de MS, pelo enchimento do rúmenretículo e pela baixa taxa de passagem que normalmente ocorre em animais alimentados com rações com altos teores de fibra.

Não houve diferença $(\mathrm{P}>0,05)$ na ingestão de MS também entre as silagens não amonizada e amonizada. Este resultado provavelmente está relacionado ao fato de não se ter colocado lona na parte inferior do silo, o que resultou na volatilização da amônia e impossibilitou a melhoria desejada no consumo de MS do capim-elefante amonizado.

Segundo Fadel et al. (2003), geralmente a amonização de volumosos de baixa qualidade eleva os teores de PB em 6,00 pontos percentuais. Neste trabalho, a amonização elevou apenas em 2,45 pontos percentuais, o que pode ser considerado, uma vez que dos $2,2 \%$ de nitrogênio ( $5 \%$ na MS de uréia com $44 \%$ de N) acrescentado à silagem apenas $0,39 \%$ ficou retido na massa, o que indica prováveis perdas para o solo pela produção de efluentes após a forragem ser ensilada. Sabe-se que a incorporação da uréia praticamente elimina a volatilização de amônia (Lara Cabezas et al., 2000), pois aumenta o contato entre a uréia e o solo favorecendo a adsorção de $\mathrm{NH}_{4}{ }^{+}$aos colóides orgânicos e inorgânicos (Silva et al., 1995) e solos com alta CTC apresentam grande capacidade de retenção de $\mathrm{NH}_{4}{ }^{+}$(Wang \& Alva, 2000).

Para o consumo de MS expresso em \%PC, Silva et al. (2005) observaram redução quando o FC representou $18,47 \%$ da MS, o que não ocorreu neste experimento. Isso provavelmente se deve ao nível de farelo de cacau, que correspondeu a $16 \%$ da MS da dieta. Em outros trabalhos, também não foi observada redução no consumo de MS com a inclusão de farelo de cacau, como os estudos realizados por Silva et al. (2005), com 9,9\% de farelo de cacau em dietas para cabras 
Tabela 4 - Consumo de MS (kg/dia e \%PC) em ovinos alimentados com as dietas experimentais

\begin{tabular}{|c|c|c|c|c|c|c|c|}
\hline \multirow[t]{2}{*}{ Item } & \multirow[t]{2}{*}{ Unidade } & \multirow[t]{2}{*}{ Capim-elefante } & \multicolumn{3}{|c|}{ Concentrado } & \multirow[t]{2}{*}{ Média } & \multirow[t]{2}{*}{$\mathrm{CV}(\%)$} \\
\hline & & & Controle & $40 \% \mathrm{FC}$ & $40 \%$ TD & & \\
\hline \multirow[t]{6}{*}{ MS } & $\mathrm{kg} / \mathrm{dia}$ & Não-amonizado & 1,001 & 0,987 & 0,861 & $0,950 \mathrm{~A}$ & \multirow{3}{*}{11,64} \\
\hline & & Amonizado & 0,896 & 1,037 & 0,785 & $0,906 \mathrm{~A}$ & \\
\hline & & Média & $0,948 \mathrm{ab}$ & $1,012 \mathrm{a}$ & $0,823 b$ & & \\
\hline & \multirow[t]{3}{*}{$\% \mathrm{PC}$} & Não-amonizado & 3,48 & 3,64 & 3,16 & $3,43 \mathrm{~A}$ & \multirow[t]{3}{*}{6,70} \\
\hline & & Amonizado & 3,36 & 3,67 & 2,96 & $3,33 \mathrm{~A}$ & \\
\hline & & Média & $3,42 \mathrm{a}$ & $3,65 \mathrm{a}$ & $3,06 \mathrm{~b}$ & & \\
\hline
\end{tabular}

Médias seguidas de mesma letra minúscula na mesma linha, ou de mesma letra maiúscula em mesma coluna, não diferem entre si pelo teste Tukey a $5 \%$ de probabilidade.

$\mathrm{FC}=$ farelo de cacau; $T \mathrm{D}=$ torta de dendê.

em lactação, e Pires et al. (2004), com inclusão de $15 \%$ de farelo de cacau em dietas para ovinos.Isso pode indicar que o limite para inclusão desse subproduto na MS da dieta de ruminantes é de 16 a $18 \%$.

Rodrigues Filho et al. (1996) observaram redução no consumo de MS em ovelhas alimentadas com dietas contendo 29,7\% de torta de dendê na MS total em substituição ao farelo de trigo. Silva et al. (2000) constataram redução no consumo de MS em bezerros de 60 a 120 dias com o acréscimo de torta de dendê no concentrado e concluíram que esta redução estaria relacionada, provavelmente, à menor palatabilidade e ao alto teor de fibra da torta de dendê.

Os consumos de MS em $\mathrm{g} / \mathrm{kg}^{0,75}$ observados neste trabalho para a dieta controle e com $40 \%$ de farelo de cacau (78,46 e 83,78 g/kg0,75 respectivamente) parecem representar a capacidade de ingestão de ovinos Santa Inês nesta faixa de peso (Barros et al., 1994; Alves et al., 2003; FurushoGarcia et al., 2004).

Nesta pesquisa, as diferenças nos teores de PB das dietas com silagem amonizada ou não-amonizada $(\mathrm{P}<0,05)$ foram em média 1,81 pontos percentuais.Essa diferença não foi suficiente para elevar o consumo de MS, possivelmente porque os concentrados foram isoprotéicos (Tabela 2) e houve pequeno aumento nos teores de nitrogênio nãoprotéico (NNP) em decorrência da amonização (apenas 2,45 pontos percentuais).Zundt et al. (2002), revisando sobre a influência do nível de PB sobre o consumo de MS, afirmaram que à medida que o nível de $\mathrm{PB}$ foi elevado de 8 a 9\% para 13 a $14 \%$, ocorreram aumentos no consumo de alimentos. No entanto, o efeito da adição de proteína sobre o consumo é mais sensível quando a proteína se encontra em níveis muito baixos, limitando a atividade microbiana do rúmen, o que não ocorreu neste trabalho (Tabela 3), uma vez que as dietas continham teores superiores a 7\%, considerados valores mínimos para o bom desempenho ruminal (Van Soest, 1994).

Verificou-se efeito $(\mathrm{P}<0,05)$ dos volumosos e dos concentrados sobre o consumo de $\mathrm{PB}$ em \% PC, entretanto, não houve efeito $(\mathrm{P}>0,05)$ da interação volumoso $\times$ concentrado (Tabela 5). Estes resultados são explicados pelo consumo de MS em \%PC, que foi menor nos animais alimentados com a dieta com $40 \%$ TD. Também não houve efeito $(\mathrm{P}>0,05)$ das silagens não amonizada e amonizada nem da interação volumoso $\times$ concentrado sobre os consumos de FDN e FDA, em \%PC (Tabela 5). Os consumos de FDN e FDA diferiram $(\mathrm{P}<0,05)$ entre os animais. Os consumos de FDN nos animais alimentados com os concentrados contendo $40 \%$ de FC ou $40 \%$ de TD foram superiores aos obtidos nos animais alimentados com o concentrado padrão. O consumo de FDN tendeu a ser menor entre os animais alimentados com o concentrado padrão, provavelmente em virtude do menor teor de FDN desse concentrado. Os consumos de FDN em \% PC encontrados neste trabalho foram superiores aos sugeridos por Van Soest (1994), de 0,8 a 1,2\% PC.

A utilização dos subprodutos elevou os teores de FDN das dietas (Tabela 2), que foram maiores naquelas com $40 \%$ de FC e $40 \%$ de TD. Resultado semelhante foi observado por Silva et al. (2005), que utilizaram FC e TD na alimentação de cabras em lactação, nos níveis 0,15 e $30 \%$ e verificaram aumento nos teores de FDN das dietas contendo subprodutos, entretanto, não foi verificada diferença na ingestão de FDN das rações.

Neste experimento, a utilização de $40 \% \mathrm{FC}$ provocou maior $(\mathrm{P}<0,05)$ consumo de $\operatorname{FDN}(32,79 ; 40,54$ e $37,60 \mathrm{~g} / \mathrm{kg}^{0,75}$ para os tratamentos controle, $40 \%$ FC e $\left.40 \% \mathrm{TD}\right)$ em comparação ao concentrado padrão, provavelmente porque o farelo de cacau é mais rico nesta fração fibrosa. Pires et al. (2002), utilizando os níveis 0, 10 e 20\% de FC na MS em dietas para novilhos, não observaram diferença no consumo de FDN, em \% PC e g FDN/kg 0,75 , entre os níveis estudados. Entretanto, o consumo de g FDN $/ \mathrm{kg}^{0,75}$ tendeu a ser maior nos animais alimentados com a dieta com $20 \%$ de FC.

Pires et al. (2004), utilizando os níveis 0 e $15 \%$ de FC em dietas para ovinos, observaram valor semelhante $(1,76 \%)$ ao obtido para consumo de FDN em \% PC neste trabalho 
Tabela 5 - Consumo de PB, FDN e FDA (\%PC) em ovinos alimentados com as dietas experimentais

\begin{tabular}{|c|c|c|c|c|c|c|}
\hline \multirow[t]{2}{*}{ Item } & \multirow[t]{2}{*}{ Capim-elefante } & \multicolumn{3}{|c|}{ Concentrado } & \multirow[t]{2}{*}{ Média } & \multirow[t]{2}{*}{$\mathrm{CV}(\%)$} \\
\hline & & Controle & $40 \% \mathrm{FC}$ & $40 \% \mathrm{TD}$ & & \\
\hline \multirow[t]{3}{*}{ PB } & Não-amonizado & 0,349 & 0,371 & 0,298 & $0,339 \mathrm{~B}$ & \multirow[t]{3}{*}{6,24} \\
\hline & Amonizado & 0,400 & 0,425 & 0,320 & $0,382 \mathrm{~A}$ & \\
\hline & Média & $0,374 \mathrm{a}$ & $0,398 \mathrm{a}$ & $0,309 b$ & & \\
\hline \multirow[t]{3}{*}{ FDN } & Não-amonizado & 1,45 & 1,77 & 1,72 & $1,65 \mathrm{~A}$ & \multirow[t]{3}{*}{7,92} \\
\hline & Amonizado & 1,41 & 1,78 & 1,58 & $1,59 \mathrm{~A}$ & \\
\hline & Média & $1,43 b$ & $1,77 \mathrm{a}$ & $1,65 \mathrm{a}$ & & \\
\hline \multirow[t]{3}{*}{ FDA } & Não-amonizado & 0,66 & 0,95 & 0,87 & $0,83 \mathrm{~A}$ & \multirow[t]{3}{*}{8,53} \\
\hline & Amonizado & 0,63 & 0,92 & 0,77 & $0,77 \mathrm{~A}$ & \\
\hline & Média & $0,64 \mathrm{c}$ & $0,94 a$ & $0,82 b$ & & \\
\hline
\end{tabular}

Médias seguidas de mesma letra minúscula na mesma linha, ou de mesma letra maiúscula em mesma coluna, não diferem entre si pelo teste Tukey a $5 \%$ de probabilidade.

$F C=$ farelo de cacau; TD = torta de dendê

$(1,77 \%)$. Uma vez que a porcentagem de FC neste experimento foi $33,3 \%$ superior à obtida em experimento realizado por Pires et al. (2004), esperava-se obter maior consumo de FDN em \% PC neste estudo.

Ressalta-se que teores elevados de FDN na dieta (Tabela 2) limitam o consumo de MS (Tabela 4), como observado para o concentrado contendo 40\%TD. Para o consumo de FDN em porcentagem do peso corporal, não se observou interação volumoso $\times$ concentrado $(\mathrm{P}>0,05)$.

A amonização do capim-elefante não provocou diferença $(\mathrm{P}>0,05)$ no consumo de FDA das silagens (Tabela 5). $\mathrm{O}$ consumo de FDA diferiu $(\mathrm{P}<0,05)$, em \% PC, entre os concentrados experimentais e foi maior nos animais alimentados com o concentrado contendo $40 \% \mathrm{FC}$ e menor naqueles alimentados com o concentrado padrão. Essa diferença obtida com a inclusão de subprodutos está relacionada ao menor peso dos animais que consumiram o concentrado com $40 \% \mathrm{FC}$, pois as dietas com $40 \% \mathrm{FC}$ e $40 \%$ TD consumidas (quantidade oferecida menos as sobras) continham 25,61 e 26,80\% de FDA, respectivamente.

A amonização não influenciou os consumos de NDT, CT e CFN em \%PC. O consumo de CT (Tabela 6) diferiu $(\mathrm{P}<0,05)$ apenas entre os animais alimentados com o concentrado com $40 \%$ TD. A inclusão dos subprodutos reduziu o consumo de CNF em \%PC (Tabela 6), que foi menor nos animais alimentados com o concentrado contendo 40\% TD em comparação àquele com $40 \% \mathrm{FC}$. O consumo de NDT (Tabela 6) em \%PC foi menor $(\mathrm{P}<0,05)$ nos animais alimentados com a dieta com $40 \% \mathrm{TD}$, o que pode ser atribuído ao consumo de MS (Tabela 4).

Houve efeito $(\mathrm{P}<0,05)$ de volumoso e de concentrado sobre o ganho de peso diário (GPD) em gramas (Tabela 7). Entretanto, essa variável não foi influenciada $(\mathrm{P}>0,05)$ pela interação volumoso $\times$ concentrado, provavelmente em razão do maior teor protéico da silagem amonizada, que ocasiona aumento da ingestão desse nutriente, em \%PC, favorecendo a fermentação ruminal e a taxa de passagem pelo trato gastrintestinal dos animais.

As médias de GPD obtidas neste trabalho foram superiores às encontradas por Rodrigues Filho et al. (1998), que avaliaram a utilização de torta de dendê na alimentação de ovinos e observaram ganho de peso de 49,30 g nos animais alimentados com $100 \%$ de volumoso; 57,50 g nos alimentados com volumoso + concentrado (100\% de TD); 90,40 g naqueles alimentados com volumoso + concentrado $(50 \%$ de TD $+50 \%$ de milho) e $87,70 \mathrm{~g}$ naqueles alimentados com volumoso + concentrado ( $20 \%$ de TD).

Os valores encontrados neste trabalho foram inferiores aos obtidos por Pires et al. (2004), tanto para o concentrado sem FC quanto para aquele com $40 \%$ FC. Esses autores utilizaram silagem de sorgo ad libitum com 0 ou $15 \%$ de FC na MS em substituição ao concentrado padrão na alimentação de ovinos eobservaramganho de peso médio diário de 90,45 e 82,9 g nos animais alimentados com as dietas sem e com farelo de cacau. Esse pior resultado, no entanto, pode ser atribuído ao maior peso dos animais utilizados (30 kg de PC).

O desempenho dos animais neste trabalho não parece ter sido influenciado pelo consumo de MS, apesar de ter sido baixo em comparação ao valor preconizado pelo NRC (1985), de $100 \mathrm{~g} / \mathrm{kg}^{0,75} / \mathrm{dia}$. No entanto, trabalhos semelhantes realizados no Brasil com ovinos Santa Inês na mesma faixa de peso ingerindo MS e EM relatam ganhos de peso maiores (Alves et al., 2003; Furusho-Garcia et al., 2004).

O menor desempenho observado neste trabalho pode ser atribuído à relação proteína:energia, que afetou a conversão alimentar dos animais (Zundt et al., 2002), fato comprovado pela melhor conversão alimentar $(\mathrm{P}<0,05)$ dos animais alimentados com silagem amonizada (Tabela 7). Contudo, esperava-se que ocorressem maiores diferenças no desempenho dos animais alimentados com as dietas com silagem amonizada e farelo de cacau e torta de dendê em 
Tabela 6 - Consumos de carboidratos totais (CT), carboidratos não-fibrosos (CNF) e nutrientes digestíveis totais (NDT)(\%PC) em ovinos alimentados com as dietas experimentais

\begin{tabular}{|c|c|c|c|c|c|c|}
\hline \multirow[t]{2}{*}{ Item } & \multirow[t]{2}{*}{ Capim-elefante } & \multicolumn{3}{|c|}{ Concentrado } & \multirow[t]{2}{*}{ Média } & \multirow[t]{2}{*}{$\mathrm{CV}(\%)$} \\
\hline & & Controle & $40 \% \mathrm{FC}$ & $40 \% \mathrm{TD}$ & & \\
\hline \multirow[t]{3}{*}{ CT } & Não-amonizado & 2,95 & 2,99 & 2,67 & $2,87 \mathrm{~A}$ & 5,72 \\
\hline & Amonizado & 2,77 & 2,88 & 2,48 & $2,71 \mathrm{~A}$ & \\
\hline & Média & $2,86 \mathrm{a}$ & $2,94 \mathrm{a}$ & $2,58 \mathrm{~b}$ & & \\
\hline \multirow[t]{3}{*}{$\mathrm{CNF}$} & Não-amonizado & 2,08 & 1,89 & 1,42 & $1,80 \mathrm{~A}$ & 5,73 \\
\hline & Amonizado & 2,05 & 1,90 & 1,36 & $1,77 \mathrm{~A}$ & \\
\hline & Média & $2,06 \mathrm{a}$ & $1,89 \mathrm{~b}$ & $1,39 \mathrm{c}$ & & \\
\hline \multirow[t]{3}{*}{ NDT } & Não-amonizado & 2,24 & 2,21 & 1,96 & $2,14 \mathrm{~A}$ & 15,30 \\
\hline & Amonizado & 2,64 & 2,33 & 1,85 & $2,28 \mathrm{~A}$ & \\
\hline & Média & $2,44 a$ & $2,27 \mathrm{ab}$ & $1,90 \mathrm{~b}$ & & \\
\hline
\end{tabular}

Médias seguidas de mesma letra minúscula na mesma linha, ou de mesma letra maiúscula em mesma coluna, não diferem entre si pelo teste Tukey a $5 \%$ de probabilidade.

$\mathrm{FC}=$ farelo de cacau; $T \mathrm{D}=$ torta de dendê.

Tabela 7 - Ganho de peso diário (GP) e conversão alimentar (CA) em ovinos alimentados com as dietas experimentais

\begin{tabular}{|c|c|c|c|c|c|c|}
\hline & \multirow[t]{2}{*}{ Capim-elefante } & \multicolumn{3}{|c|}{ Concentrado } & \multirow[t]{2}{*}{ Média } & \multirow[t]{2}{*}{$\mathrm{CV}(\%)$} \\
\hline & & Controle & $40 \% \mathrm{FC}$ & $40 \% \mathrm{TD}$ & & \\
\hline \multirow[t]{3}{*}{ GP } & Não-amonizado & 117,5 & 81,5 & 102,6 & $100,5 \mathrm{~B}$ & 14,35 \\
\hline & Amonizado & 160,3 & 119,0 & 98,4 & $125,9 \mathrm{~A}$ & \\
\hline & Média & $138,9 \mathrm{a}$ & $100,3 b$ & $100,5 b$ & & \\
\hline \multirow[t]{3}{*}{ CA } & Não-amonizado & $8,63 \mathrm{bA}$ & $12,16 \mathrm{aA}$ & $8,43 \mathrm{bA}$ & 9,74 & 8,70 \\
\hline & Amonizado & $5,59 \mathrm{bB}$ & $8,81 \mathrm{aB}$ & $8,00 \mathrm{aA}$ & 7,46 & \\
\hline & Média & 7,11 & 10,48 & 8,21 & & \\
\hline
\end{tabular}

Médias seguidas de mesma letra minúscula na mesma linha, ou de mesma letra maiúscula em mesma coluna, não diferem entre si pelo teste Tukey a $5 \%$ de probabilidade.

$F C=$ farelo de cacau; TD = torta de dendê.

relação à silagem não amonizada, principalmente porque esses subprodutos apresentam, respectivamente, 52,20 e $49,43 \%$ da PB na forma insolúvel em detergente neutro (Silva et al., 2005).

A ingestão de PB $\left(7,02\right.$ a $\left.8,57 \mathrm{~g} / \mathrm{kg}^{0,75}\right)$, para todas as dietas, foi inferior à preconizada pelo NRC (1985), que recomenda ingestão diária de $12,25 \mathrm{~g} / \mathrm{kg}^{0,75}$ (137 g de PB para $25 \mathrm{~kg}$ de $\mathrm{PC}$ ) para ganho de peso de $150 \mathrm{~g} /$ dia em ovinos com $25 \mathrm{~kg}$ de PC.

As relações utilizadas neste trabalho foram todas inferiores (42,39; 47,84 e 44,62 g PB/Mcal de EM para as dietas controle, $40 \%$ de $\mathrm{FC} \mathrm{e} 40 \%$ de $\mathrm{TD}$, respectivamente) às utilizadas por Alves et al. (2003), de 87,16; 77,25 e 69,39 g PB/Mcal de EM, e Furusho-Garcia et al. (2004), de 63,92; 65,04 e 61,95 g PB/Mcal de EM. Estes resultados estão de acordo com os descritos por Zundt et al. (2002), que, ao utilizarem níveis crescente de proteína em dietas para ovinos, não observaram efeito do nível de proteína sobre o consumo de MS, porém, constataram elevação significativa no ganho de peso.

Pela análise do custo da alimentação por ganho de PC, todas as dietas permitiram lucratividade parcial positiva, o que significa que a exploração é auto-sustentável.
A amonização da silagem elevou em $8 \%$ o custo da alimentação, mas proporcionou redução em $18,4 \%$ por kg de peso vivo produzido. Além disso, elevou em $77,2 \%$ a lucratividade parcial em relação à obtida com dietas à base de silagem não amonizada. A inclusão dos subprodutos reduziu os custos por $\mathrm{kg}$ de MS sem aumentar a lucratividade por kg de ganho de peso. Os resultados econômicos com a inclusão de farelo de cacau e torta de dendê foram, respectivamente, 49,7 e 64,3\% do lucro obtido com a dieta controle.

Estes resultados demonstram que nem sempre o fornecimento de dietas mais baratas resulta em maior retorno econômico, indicando que a eficiência alimentar foi o fator que mais interferiu no resultado final, exercendo mais influência que o custo por kg da ração.

\section{Conclusões}

A amonização é uma prática que pode ser utilizada em silagens de capim em idade avançada, pois melhor a o desempenho dos animais e proporciona e maior lucratividade parcial. A inclusão de $40 \%$ de farelo de cacau e de $40 \%$ de torta de dendê em substituição ao concentrado, correpondendo a $16 \%$ da dieta total, precisa de maiores estudos, pois reduz 
Tabela 8 - Custo da alimentação por ganho de peso corporal (GP)

\begin{tabular}{|c|c|c|c|c|c|}
\hline & \multirow[t]{2}{*}{ Capim-elefante } & \multicolumn{3}{|c|}{ Concentrado } & \multirow[t]{2}{*}{ Média } \\
\hline & & Controle & $40 \% \mathrm{FC}$ & $40 \% \mathrm{TD}$ & \\
\hline \multirow[t]{2}{*}{ Custo em $\mathrm{R} \$ / \mathrm{kg}$ de MS } & Não-amonizado & 0,27 & 0,24 & 0,24 & 0,25 \\
\hline & Amonizado & 0,28 & 0,26 & 0,26 & 0,27 \\
\hline \multirow[t]{3}{*}{ Custo de alimentação $\mathrm{R} \$ / \mathrm{kg}$ GP } & Não-amonizado & 1,96 & 2,62 & 2,05 & 2,44 \\
\hline & Amonizado & 2,33 & 2,92 & 2,02 & 1,99 \\
\hline & Média & 1,57 & 2,29 & 2,08 & \\
\hline \multirow[t]{3}{*}{ Lucro parcial em $\mathrm{R} \$ / \mathrm{kg}$ GP } & Não-amonizado & 1,04 & 0,38 & 0,95 & 0,57 \\
\hline & Amonizado & 0,67 & 0,08 & 0,98 & 1,01 \\
\hline & Média & 1,43 & 0,71 & 0,92 & \\
\hline
\end{tabular}

Controle $=\mathrm{R} \$ 0,50 / \mathrm{kg}$ de MS; $40 \% \mathrm{FC}$ e $40 \% \mathrm{TD}=\mathrm{R} \$ 0,43 / \mathrm{kg}$ de MS; capim-elefante não-amonizado = R $\$ 0,11 ;$ capim-elefante amonizado = R $\$ 0,14 / \mathrm{kg}$ de MS; preço por $\mathrm{kg}$ de $\mathrm{PC}=\mathrm{R} \$ 3,00$.

o ganho de peso e a lucratividade parcial em relação à dieta à base de milho e soja

\section{Literatura Citada}

ALVES, K.S.; CARVALHO, F.F.R.; VÉRAS, A.S.C. et al. Níveis de energia em dietas para ovinos Santa Inês: desempenho. Revista Brasileira de Zootecnia, v.32, n.6, p.1937-1944, 2003 (supl 2).

BARROS, N.B.; FIGUEIREDO, E.A.P.; FERNANDES, F.D. et al. Ganho de peso e conversão alimentar de cordeiros cruzas no estado do ceará. Pesquisa Agropecuária Brasileira, v.29, n. 8, p.1313-1317, 1994.

BERTIPAGLIA, L.M.A.; LUCA, S.; MELO, G.M.P. et al. Avaliação de fontes de urease na amonização de fenos de Brachiaria brizantha com dois teores de umidade. Revista Brasileira de Zootecnia, v.34, n.2, p.378-386, 2005.

CÂNDIDO, M.J.D.; NEIVA, J.N.M.; PIMENTEL, J.C.M. et al. Avaliação do valor nutritivo do bagaço de cana-de-açúcar amonizado com uréia. Revista Brasileira de Zootecnia, v.28, n.5, p.928-935, 1999.

CARVALHO, G.G.P.; PIRES, A.J.; VELOSO, C.M. et al. Valor nutritivo do bagaço de cana-de-açúcar amonizado com quatro doses de uréia. Pesquisa Agropecuária Brasileira, v.41, n.1, p.125-132, 2006.

COMPÊNDIO BRASILEIRO DE ALIMENTAÇÃO ANIMAL. Ministério da Agricultura e Abastecimento. Matéria-prima. Brasília: Sindirações/ANFAR: CBNA, SDR/MA, 1998. p.12.

FADEL, R.; ROSA, B.; OLIVEIRA, I.P. et al. Avaliação de diferentes proporções de água e de uréia sobre a composição bromatológica da palha de arroz. Ciência Animal Brasileira, v.4, n.2, p.101$107,2003$.

FERRARI JR.E.; LAVEZZO, W. Qualidade da silagem de capim elefante (Pennisetum purpureum Schum.) emurchecido ou acrescido de farelo de mandioca. Revista Brasileira de Zootecnia, v.30, n.5, p.1424-1431, 2001.

FURUSHO-GARCIA, I.F.; PEREZ, J.R.O.; BONABURIO, S. et al. Desempenho de cordeiros Santa Inês puros e cruzas Santa Inês com Texel, Ilhe de France e Berganácia. Revista Brasileira de Zootecnia, v.33, n.6, p1591-1603, 2004.

INSTITUTO BRASILEIRO DE GEOGRAFIA E ESTATÍSTICA IBGE. Produção agrícola municipal (PAM) : quantidade produzida. Disponível em: <http://www.sidra.ibge.gov.br/bda/ tabela/lestabl.asp?c=1613\&z=t\&o=11.> Acesso em: 8/3/2004.

LARA CABEZAS, W.A.R.;TRIVELIN, P.C.P; KORNDÔRFER, G.H et al. Balanço da adubação nitrogenada sólida e fluida de cobertura na cultura do milho em sistema plantio direto no Triângulo Mineiro (MG). Revista Brasileira de Ciências do Solo, v.24, p36-376, 2000.
LAVEZZO, W. Ensilagem do capim-elefante. In: SIMPÓSIO SOBRE MANEJO DA PASTAGEM, 10., 1994, Piracicaba. Anais... Piracicaba: Fundação de Estudos Agrários Luiz de Queiroz, 1994. p.169-275.

NATIONAL RESEARCH COUNCIL - NRC. Nutrient requirements of sheep. 6.ed. Washington, D.C.: National Academy of Science, $1985.99 \mathrm{p}$.

PIRES, A.J.V.; CARVALHO JR., J.N.; SILVA, F.F. et al. Farelo de cacau (Theobroma cacao L.) na alimentação de ovinos. Revista Ceres, v.51, n.293, p.33-43, 2004

PIRES, A.J.V.; VIEIRAS, V.F.; SILVA, F.F. et al. Farelo de cacau (Theobroma cacao) na alimentação de novilhos. In: REUNIÃO ANUAL DA SOCIEDADE BRASILEIRA DE ZOOTECNIA, 39. 2002, Recife. Anais... Recife: Sociedade Brasileira de Zootecnia, 2002. (CD-ROM).

REIS, R.A.; GARCIA, R.; QUEIROZ, A.C. et al. Efeitos da amonização sobre a qualidade dos fenos de gramíneas tropicais. Pesquisa Agropecuária Brasileira, v.26, n.8, p.1183-91, 1991.

REIS, R.A.; RODRIGUES, L.R.A.; PEREIRA, J.R.A. et al. Composição química e digestibilidade de fenos tratados com amônia anidra ou uréia. Revista Brasileira de Zootecnia, v.30, n.3, p.666-673, 2001.

RODRIGUES FILHO, J.A.; CAMARÃO, A.P.; AZEVEDO, G.P.C. et al. Composição química da torta de amêndoa de dendê produzida na região Nordeste do Estado do Pará. In: REUNIÃO DA SOCIEDADE BRASILEIRA DE ZOOTECNIA, 35., 1998, Botucatu. Anais... Botucatu: Sociedade Brasileira de Zootecnia, 1998. v.1, p.113-115.

RODRIGUES FILHO, J.A.; CAMARÃO, A.P.; BATISTA, H.A.M. et al. Níveis de torta de dendê em substituição ao farelo de trigo no consumo voluntário e digestibilidade de concentrados. In: REUNIÃO DA SOCIEDADE BRASILEIRA DE ZOOTECNIA, 35., 1996, Fortaleza. Anais... Fortaleza: Sociedade Brasileira de Zootecnia, 1996. p.292-293.

UNIVERSIDADE FEDERAL DE VIÇOSA - UFV. Sistema para Análise Estatística e Genética - SAEG . versão 8.0. Viçosa, MG: Fundação Arthur Bernardes, 1998. (CD-ROM).

SILVA, A.J.; LIMA JR., M.A.; FERREIRA, N.C.M. et al. Perdas de amônia por volatilização proveniente da uréia aplicada a olos dos trópicos úmidos. Revista Brasileira de Ciência do Solo, v.19, p.141-144, 1995.

SILVA, D.J.; QUEIROZ, A.C. Análise de alimentos: métodos químicos e biológicos. Viçosa, MG: Universidade Federal de Viçosa, 2002. 235p.

SILVA, F.F.; PIRES, A.J.V.; OLIVEIRA, A.R.A. et al. Torta de dendê em dietas de bezerros leiteiros desmamados precocemente. In: REUNIÃO ANUAL DA SOCIEDADE BRASILEIRA DE ZOOTECNIA, 37., 2000, Viçosa, MG. Anais... Viçosa, MG: Sociedade Brasileira de Zootecnia, 2000. (CD-ROM).

SILVA, H.G.O.; PIRES, A.J.V.; SILVA, F.F. et al. Farelo de cacau (Theobroma cacao L.) e torta de dendê (Elaeis guineensis, 
Jacq) na alimentação de cabras em lactação: consumo e produção de leite. Revista Brasileira de Zootecnia, v.34, n.5, p.1790$1798,2005$.

SILVA, H.G.O.; PIRES, A.J.V.; CUNHA NETO, P.A. et al. Digestibilidade de dietas contendo silagem de capim-elefante amonizado e farelo de cacau ou torta de dendê em ovinos.

Revista Brasileira de Zootecnia, v.36, n.2, p.499-506, 2007.

SNIFFEN, C.J.; O'CONNOR, J.D.; Van SOEST, P.J. et al. Net carbohydrate and protein system for evaluating cattle diets: II. Carbohydrate and protein availability. Journal of Animal Science, v.70, p.3562-3577, 1992.

SOUZA, A.L.; GARCIA, R.; PEREIRA, O.G. et al. Valor nutritivo da casca de café tratada com amônia anidra. Revista Ceres, v.26, p.669-681, 2002.

Van SOEST, P.J. Nutritional ecology of the ruminant. 2.ed. Ithaca: Cornell University Press, 1994. 476p.
WANG, F.L.; ALVA, A.K. Ammonium adsorption and desorption in sandy soils. Soil Science Society American Journal, v.64, p.1669-1674, 2000.

WEISS, W. Energy prediction equations for ruminant. In: CORNELL NUTRITION CONFERENCE FOR FEED MANUfACTURERS, 61., 1999, Ithaca. Proceedings... Ithaca: Cornell University, 1999. p.176-185.

WILSON, J.R. Structural and anatomical traits of forage influencing their nutritive value for ruminants. In: SIMPÓSIO INTERNACIONAL SOBRE PRODUÇÃO ANIMAL EM PASTEJO, 1997, Viçosa, MG. Anais... Viçosa, MG: Universidade Federal de Viçosa, 1997. p.173-208.

ZUNDT, M.; MACEDO, F.A.F. ; MARTINS, E.N. et al. Desempenho de cordeiros alimentados com diferentes níveis protéicos. Revista Brasileira de Zootecnia, v.31, n.3, p.1307-1314, 2002. 